\title{
COCOONS AND YOUNG OF CONIOPTERYX VICINA.
}

\section{BY T. H. EMERTON, BOSTON, MASS.}

While hunting for spiders under leaves on the ground at Allston, a suburb of Boston, in November, I found the cocoons of this neuropterons insect attached to oak leaves and resembling the egg cocoons of small spiders like Micaria and Castaneira. The cocoons were white and had fine parallel wrinkles across the upper surface, in this differing from spider cocoons, which are usually smooth. In nearly every case the cocoons werc oil small broken pieces of leaves of last season's growth. The under side of the cocoon is thin and attached to the leaf by its whole surface. The upper side is formed by a flat ring sometimes thickened on the inner edge and a transversely wrinkled cover which is not attachel to the inner edge of the ring but beyond it "1: 7 the outer border of the cocoon, as shown in the section. The mature insect tears a hole
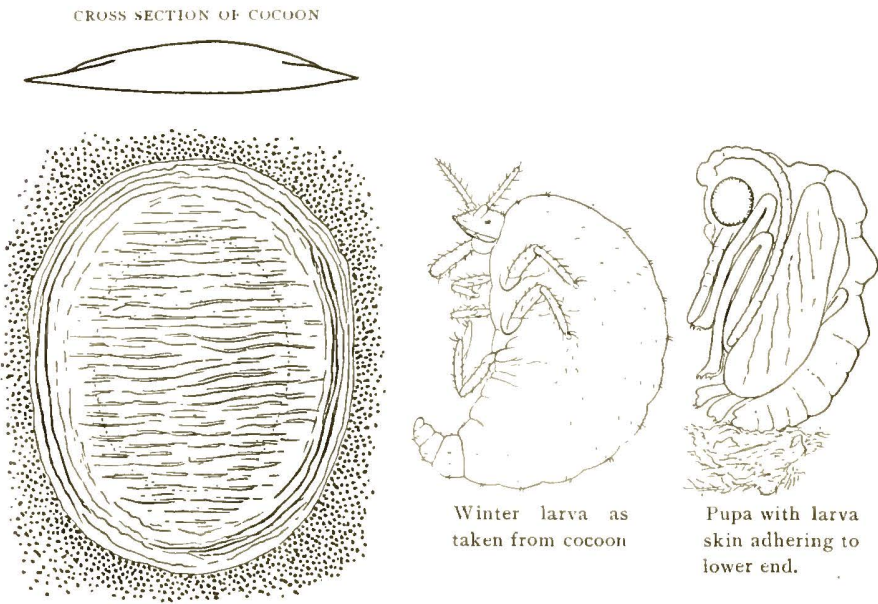

Pupa with larva skin adhering to lower end. 
in the upper side large enough to crawl through, and leaves the pupa skin half way out.

The larva is flattened sidewise like an amphipod crustacean and lics on its side in the cocoon. It is motionless when removed, even after several days in a warm room. It resembles closely the larva of $C$. psociformis (urtis described and figured by Schlectendal in the proceedings of the Terein fur Naturkunde of Zwickau, Saxony, in I88I. The head resembles it closely and the mandibles are short and pointed as in psociformis, but the antennae ant legs: are much shorter than in that species. The whole body is roughened with fine rounded elevations and each segment is crosser by a single row of short hairs.

Schlectendal found his larve in winter under loose bark of oak trecs at Halle in cocoons resembling those of spiders and was as much astonished as I was at the discovery. He, however, concludecl that the cocoons were really those of spiders and that the larvac hal eaten the eggs. The cocoons differ in structure from any spider cocoons with which I an acpluainted and it seems more probable that they are made by the larvac themselves when abont to hibernate.

I larva in a cocoon found Nuvember 9 and kept in the house in a tight bottle matured and came out of the cocom January 3o. Cocoms collected January $3 \mathrm{I}$ and then containing larva hat pupate in them March $\mathrm{I}$, and the maturc insects came out March I 2 to April 1. 

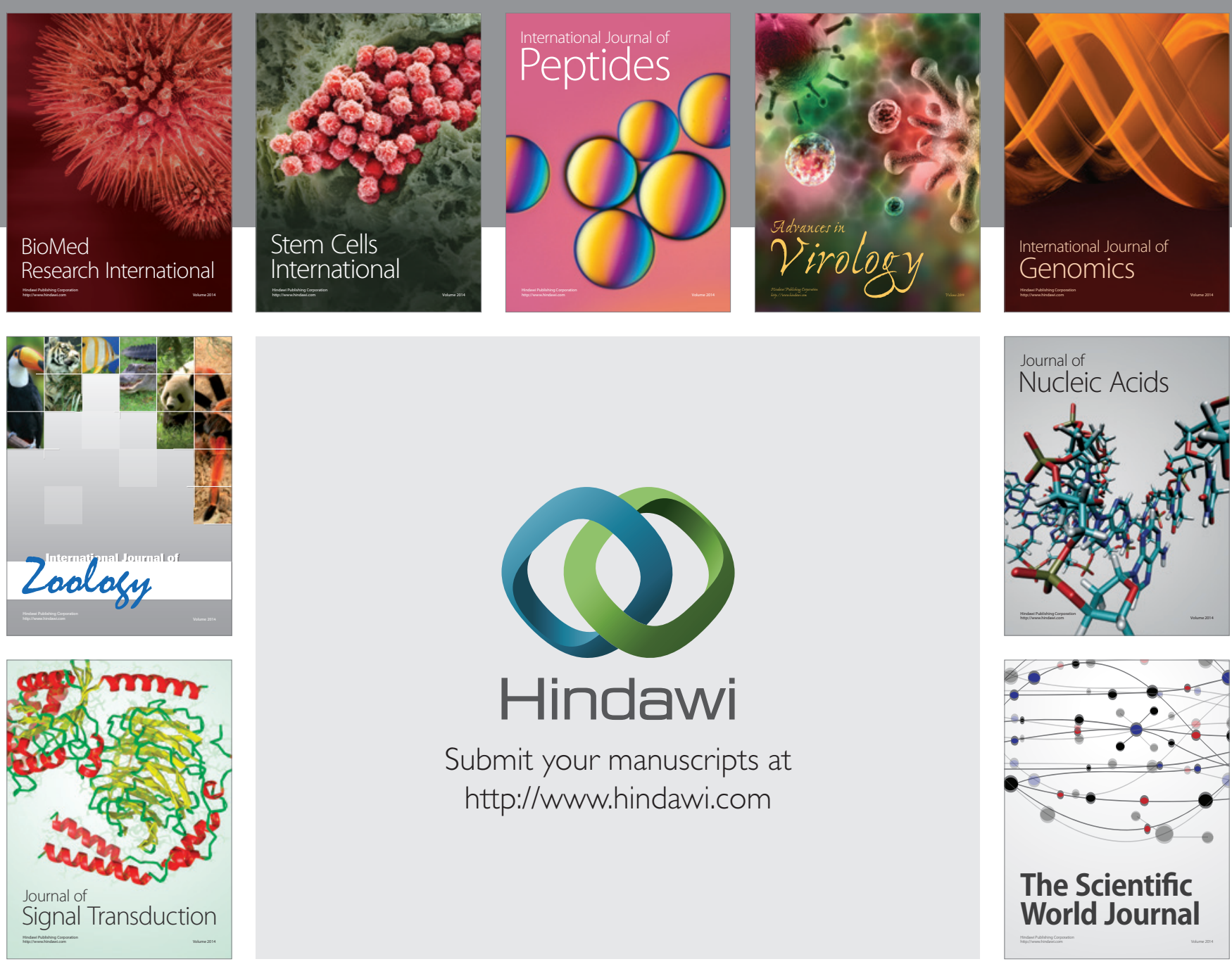

Submit your manuscripts at

http://www.hindawi.com
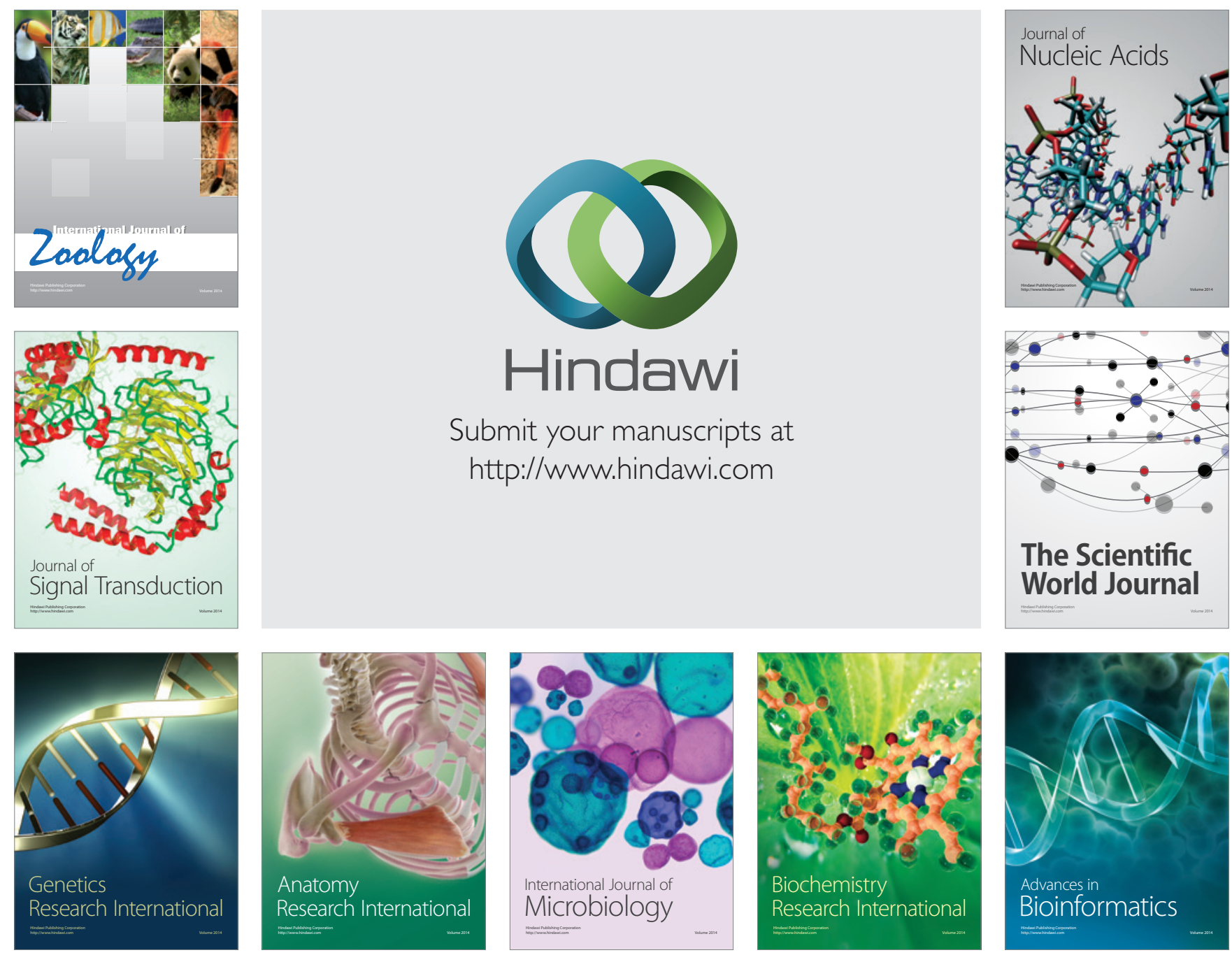

The Scientific World Journal
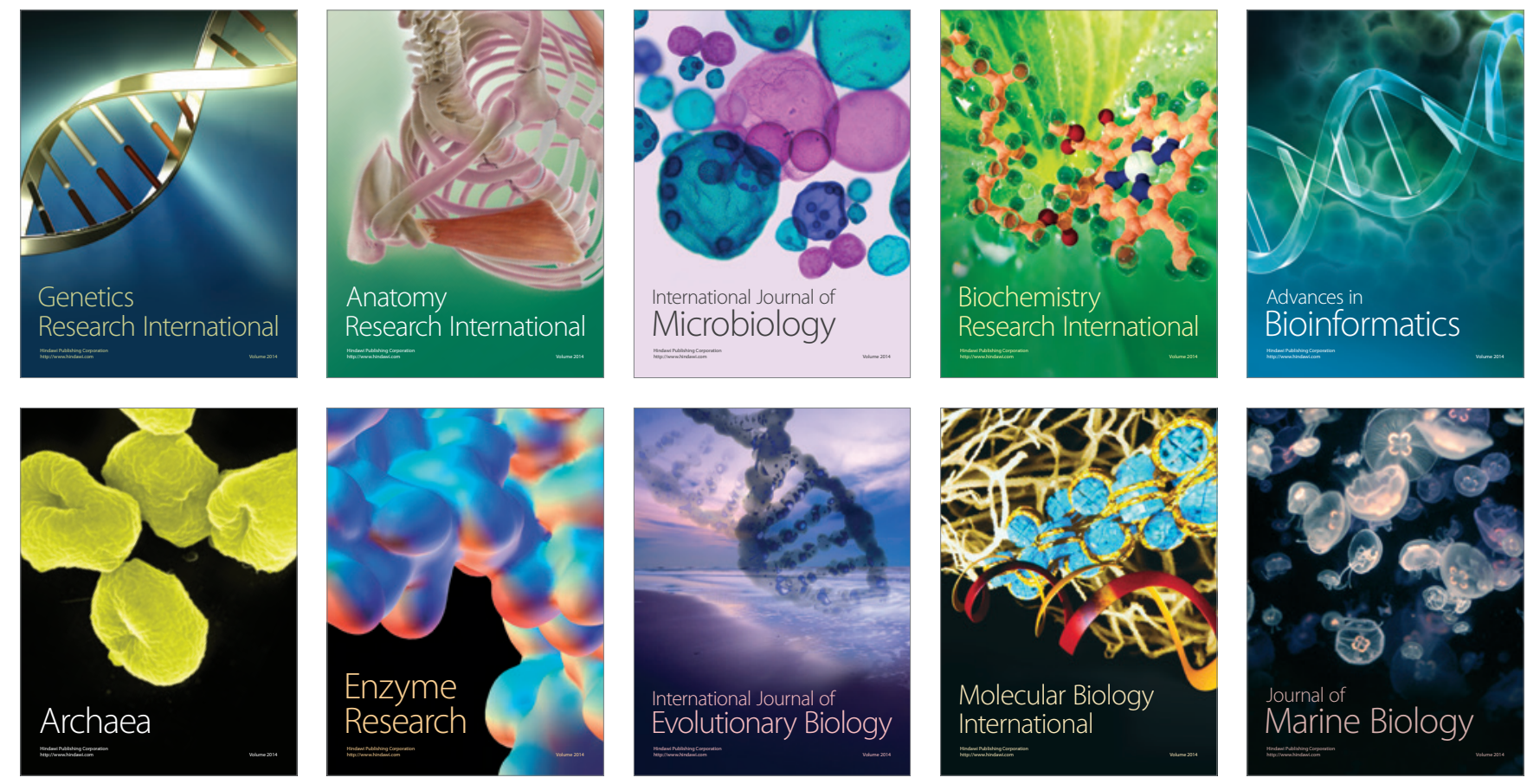